\title{
An evaluation of methods for partitioning eddy covariance-measured net ecosystem exchange into photosynthesis and respiration
}

\section{Authors: Paul C. Stoy, Gabriel G. Katul, Mario B.S. Siqueira, Jehn-Yih Juang, Kimberly A. Novick, Joshua M. Uebelherr, and Ram Oren}

NOTICE: this is the author's version of a work that was accepted for publication in Agricultural and Forest Meteorology. Changes resulting from the publishing process, such as peer review, editing, corrections, structural formatting, and other quality control mechanisms may not be reflected in this document. Changes may have been made to this work since it was submitted for publication. A definitive version was subsequently published in Agricultural and Forest Meteorology, VOL\# 141, ISSUE\# 1, (December 2006), DOI 10.1016/j.agrformet.2006.09.001.

Stoy PC, Katul GG, Siqueira MBS, Juang J-Y, Novick KA, Oren R (2006) An evaluation of methods for partitioning eddy covariance-measured net ecosystem exchange into photosynthesis and respiration. Agricultural and Forest Meteorology 141: 2-18. DOI: 10.1016/ j.agrformet.2006.09.001. 


\title{
An evaluation of models for partitioning eddy covariance-measured net ecosystem exchange into photosynthesis and respiration
}

\author{
Paul C. Stoy ${ }^{\text {a,b,*, Gabriel G. Katul }}{ }^{\text {a,b }}$, Mario B.S. Siqueira ${ }^{\text {a,c }}$, Jehn-Yih Juang ${ }^{\text {a }}$, \\ Kimberly A. Novick ${ }^{\mathrm{a}}$, Joshua M. Uebelherr ${ }^{\mathrm{a}}$, Ram Oren ${ }^{\mathrm{a}}$ \\ ${ }^{a}$ Nicholas School of the Environment and Earth Sciences, Box 90328, Duke University, Durham, NC 27708-0328, United States \\ ${ }^{\mathrm{b}}$ Department of Civil and Environmental Engineering, Pratt School of Engineering, Duke University, Durham, NC, USA \\ ${ }^{\mathrm{c}}$ Departamento de Engenharia Mecânica, Universidade de Brasília, Brazil
}

Received 5 May 2006; accepted 8 September 2006

\begin{abstract}
We measured net ecosystem $\mathrm{CO}_{2}$ exchange (NEE) using the eddy covariance (EC) technique for 4 years at adjoining old field $(\mathrm{OF})$, planted pine (PP) and hardwood forest (HW) ecosystems in the Duke Forest, NC. To compute annual sums of NEE and its components - gross ecosystem productivity (GEP) and ecosystem respiration (RE) - different 'flux partitioning' models (FPMs) were tested and the resulting $\mathrm{C}$ flux estimates were compared against published estimates from $\mathrm{C}$ budgeting approaches, inverse models, physiology-based forward models, chamber respiration measurements, and constraints on assimilation based on sapflux and evapotranspiration measurements. Our analyses demonstrate that the more complex FPMs, particularly the "non-rectangular hyperbolic method', consistently produced the most reasonable $\mathrm{C}$ flux estimates. Of the FPMs that use nighttime data to estimate $\mathrm{RE}$, one that parameterized an exponential model over short time periods generated predictions that were closer to expected flux values. To explore how much 'new information' was injected into the data by the FPMs, we used formal information theory methods and computed the Shannon entropy for: (1) the probability density, to assess alterations to the flux measurement distributions, and (2) the wavelet energy spectra, to assess alterations to the internal autocorrelation within the NEE time series. Based on this joint analysis, gap-filling had little impact on the IC of daytime data, but gap-filling significantly altered nighttime data in both the probability and wavelet spectral domains.
\end{abstract}

(C) 2006 Elsevier B.V. All rights reserved.

Keywords: Eddy covariance; Information theory; Net ecosystem exchange; Gross ecosystem productivity; Ecosystem respiration; Grass field; Oak-hickory forest; Pinus taeda

\section{Introduction}

A primary goal of the United States Global Change Research Program (USGCRP) is to quantify the role of vegetation in controlling the magnitude and variability of the terrestrial carbon sink (Sarmiento and Wofsy, 1999). Eddy covariance (EC) estimates of the net ecosystem exchange of $\mathrm{CO}_{2}$ (NEE) are ideally suited for addressing this goal (Baldocchi et al., 2001) with an important caveat. To evaluate the processes that control NEE, EC data rely on models that partition NEE into its components-gross ecosystem productivity (GEP) and ecosystem respiration (RE). These 'flux partitioning' models (FPMs) can be used in turn to 'gap-fill' missing or rejected data, thereby allowing estimates of $\mathrm{CO}_{2}$ flux over long periods (Falge et al., 2001). Hence, FPMs are 
an essential tool for interpreting EC data, yet no study to date has critically examined how the choice of a given FPM affects the magnitude and variability of carbon (C) flux estimates by comparison with independent estimates of $\mathrm{C}$ flux for different ecosystems that experience similar climatic and edaphic conditions.

Here, we used the EC technique to measure NEE for 5 years at adjoining old field (OF), planted pine (PP) and broadleaf-deciduous ('hardwood', HW) ecosystems that represent a typical post-agricultural successional sequence in the southeastern United States (SE, Oosting, 1942). The study ecosystems offer a unique set-up for a comparison of FPMs because, although they experience the same climatic (e.g., geostrophic winds, cloud cover, precipitation history, air temperature) and edaphic (e.g., soil type, rooting depth) conditions, they differ substantially in friction velocity ( $u_{*}$, Fig. 1 ; Stoy et al., 2006), which is often used as the primary filter for nighttime EC measurements (Falge et al., 2001; Gu et al., 2005; Reichstein et al., 2005). These differences in $u_{*}$ are attributable to differences in roughness properties that reflect differences in foliage drag and leaf area density among the ecosystems (Poggi et al., 2004). Five-year EC time series from these three ecosystems were used to generate NEE, GEP, and RE estimates using four FPMs that differ substantially in the data source employed (i.e., daytime versus nighttime data) and complexity of the modeling procedure. These estimates were compared against the best available independent data and model results from a range of other studies that provide estimates of the magnitude and interannual variability of net primary productivity (NPP), RE, and gross primary productivity (GPP). In this way, we ensure that EC-based estimates are defensible and independently constrained to the extent that ecosystem flux inter-comparison was possible. We then diagnosed the FPMs using both direct comparison and information theory via the Shannon entropy to assess which FPM generated the most reasonable flux estimates across dissimilar vegetative types. After choosing the optimal FPM, we provide error estimates on the flux values that are obtained.

With respect to the inter-comparison, it is important to note that the independent and model-based estimates themselves are naturally prone to random and systematic errors and do not represent the unknown 'true' flux. Regardless, alongside EC-based estimates, these techniques represent the state of the art for estimating $\mathrm{C}$ flux. Therefore, estimates generated using these methods provide 'expected' flux values in the logical rather than the statistical sense. If a given FPM fails to reproduce the approximate mean and long-term variability of the independent or model-based estimates, or delivers results that conflict with logical expectations (e.g., if the fastgrowing PP ecosystem is found to be a long-term source of $\mathrm{C}$ to the atmosphere), we can conclude that this FPM should not be used for generating EC-based estimates across different vegetation types. Below we briefly describe the methods that have been employed by different studies to estimate $\mathrm{C}$ flux from the study ecosystems.

At OF, Novick et al. (2004) combined EC and leaflevel physiological measurements with a 'big-leaf' assimilation model to estimate NEE, GEP, and RE for 2001 (Table 1), and used the model to predict $C$ fluxes in the absence of soil moisture $(\theta)$ limitations. Combined with other studies, their findings suggest that the interannual variability of NEE in grassland ecosystems may be driven by changes in GEP rather than RE, and that grassland ecosystems can switch from $\mathrm{C}$ source to $\mathrm{C}$ sink with increasing $\theta$ content. The interannual variability of GEP at OF is expected to be large due to reductions in leaf

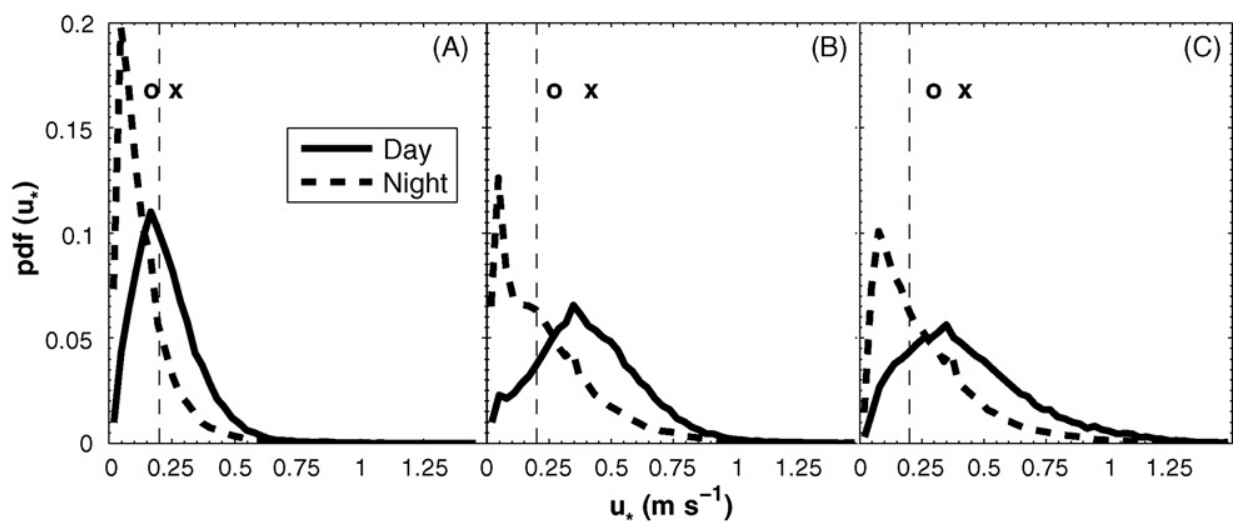

Fig. 1. The probability distribution of measured friction velocity $\left(u_{*}\right)$ for $\mathrm{OF}(\mathrm{A}), \mathrm{PP}(\mathrm{B})$ and HW (C). The symbols o and $\mathrm{x}$ indicate median $u_{*}$ for nighttime and daytime distributions, respectively. $u_{*}=0.2 \mathrm{~m} \mathrm{~s}^{-1}$, a common threshold for data filtering, is indicated by vertical dashed lines for reference. 
Table 1

Estimates of net ecosystem exchange (NEE), ecosystem respiration (RE) and gross primary productivity (GPP) at the old field (OF) and planted pine (PP) ecosystems in the Duke Forest, NC

\begin{tabular}{|c|c|c|c|c|c|c|}
\hline & \multicolumn{2}{|r|}{ Period } & \multirow{2}{*}{$\begin{array}{l}\text { NEE } \\
97\end{array}$} & GEP & \multirow{2}{*}{$\begin{array}{l}\mathrm{RE} \\
1299\end{array}$} & \multirow{2}{*}{$\begin{array}{l}\text { References } \\
\text { Novick et al. (2004) }\end{array}$} \\
\hline $\mathrm{OF}$ & & 11 April 2001-11 April 2002 & & -1202 & & \\
\hline Ecosystem & Year & NEE & GPP & $\mathrm{RE}$ & Refere & \\
\hline \multirow[t]{7}{*}{$\mathrm{PP}$} & 1997 & & $-1224^{\mathrm{a}}$ & & Luo et & Katul et al. $(2001 b)^{b}$ \\
\hline & 1998 & -580 to $-650^{\mathrm{b}},-585^{\mathrm{c}},-428^{\mathrm{d}}$ & $-1250^{\mathrm{a}},-2371^{\mathrm{f}}$ & $1920^{\mathrm{f}}$ & Falge & \\
\hline & 1999 & $-666^{\mathrm{c}},-605^{\mathrm{d}},-661^{\mathrm{e}},-746^{\mathrm{h}}$ & $-1808^{\mathrm{d}},-2287^{\mathrm{e}}$ & $1203^{\mathrm{d}}$ & Lai et & \\
\hline & 2000 & $-792^{\mathrm{e}}$ & $-2486^{\mathrm{e}}$ & & Schäfe & $3)^{\mathrm{e}}$ \\
\hline & 2001 & $-355^{\mathrm{g}}$ & $-2122^{\mathrm{g}}$ & $1767^{\mathrm{g}}$ & Hamilt & $002)^{\mathrm{f}}$ \\
\hline & 2002 & $-410^{\mathrm{g}}$ & $-2033^{g}$ & $1623^{\mathrm{g}}$ & Juang & \\
\hline & 2003 & $-449^{\mathrm{g}}$ & $-2471^{g}$ & $2022^{\mathrm{g}}$ & Hui et & \\
\hline
\end{tabular}

All flux units are $\mathrm{g} \mathrm{C} \mathrm{m}^{-2}$ year $^{-1}$. Gross ecosystem productivity (GEP) differs from GPP as described in the text.

area index (LAI) induced by drought and anthropogenic management, namely hay removal, and corresponding changes in canopy conductance. Stoy et al. (2006) showed that EC-measured evapotranspiration (ET) increased by nearly $50 \%$ between severe drought and wet years, and used a simple radiation attenuation model after Campbell and Norman (1998) to model transpiration $(T)$, which varied by over $200 \%$ among years. Given that GEP is controlled in part by $T$ due to the role of the stomata in coupling canopy $\mathrm{H}_{2} \mathrm{O}$ losses with $\mathrm{CO}_{2}$ gains, we expect that GEP will be highly sensitive to hydrologic forcing at $\mathrm{OF}$, and thus highly variable given the wide range of climatic conditions observed over the measurement period.

Estimates of GPP and/or RE at PP are available from ecosystem carbon budgeting (Hamilton et al., 2002), canopy conductance-based assimilation models (Schäfer et al., 2003), physiology-based assimilation models (Luo et al., 2001), and inverse methods using mean $\mathrm{CO}_{2}$ and mean air temperature $\left(T_{\mathrm{a}}\right)$ profiles within the canopy (Table 1, Lai et al., 2002; Juang et al., 2006). Earlier studies used EC data to estimate NEE and/or its components at PP (Table 1, Falge et al., 2001; Katul et al., 2001b; Law et al., 2002), but did not conduct a sensitivity analysis of different FPMs as performed here. We expect that the magnitude and variability of $\mathrm{C}$ fluxes at PP should approximate the independent estimates, noting that at PP the sensitivity of ET and modeled $T$ to severe drought and ice storm damage (McCarthy et al., 2006; Stoy et al., 2006) may inject more variability in GEP during 2001-2005 than in previous years.

There are no independent estimates of NEE at HW at the present, but we expect that interannual $\mathrm{C}$ flux variability will be small in a drought-tolerant (Pataki et al., 1998; Pataki and Oren, 2003) closed canopy forest that sustained minor ice storm damage and showed little interannual variability in measured ET or modeled $T$ from 2001 to 2005 (Stoy et al., 2006). The difference in chamber measured soil respiration at HW between mild and severe drought years was ca. $100 \mathrm{~g} \mathrm{C} \mathrm{m}^{-2}$ year $^{-1}(6 \%)$, and the magnitude of soil respiration at $\mathrm{HW}$ was between 10 and $26 \%$ larger than at PP (Palmroth et al., 2005). Ecosystem respiration is dominated by forest floor efflux at both ecosystems, but Mortazavi et al. (2005) used $\delta \mathrm{C}^{13}$ measurements to show that soil respiration provides a greater proportion of RE at HW compared to PP. Thus, to a first order, we expect RE at $\mathrm{HW}$ to be similar to $\mathrm{PP}$ given the similarities in forest floor efflux and the larger contribution of foliage respiration to ecosystem respiration at PP. A complication arises due to an 11.9 ha clear-cut that occurred $200 \mathrm{~m}$ south of the HW EC tower on private land in November 2002 (see Fig. 1 in Stoy et al., 2006). We conducted a two-dimensional footprint analysis to determine the impact of this clearcut on annual flux estimates at HW (Appendix A), which was estimated to be on the order of ca. $200 \mathrm{~g} \mathrm{C} \mathrm{m}^{-2}$ year $^{-1}$ for NEE and RE but less than $50 \mathrm{~g} \mathrm{C} \mathrm{m}^{-2}$ year $^{-1}$ for GEP during 2003 and negligible during other years.

For the purposes of our study, it is important to distinguish between GEP (also called gross ecosystem exchange, GEE) and gross primary productivity (GPP). GEP does not take into account recycling of $\mathrm{CO}_{2}$ within the ecosystem, such as within the leaf via re-assimilation of metabolic ('dark') respiration, or within the canopy volume and below the plane of the EC instrumentation. GEP is thus analogous, but not identical, to GPP (Goulden et al., 1997). Note also that all EC-based methods that use nighttime RE estimates to extrapolate daytime RE assume that the ratio of photorespiration energy expended by the oxygenase function of Rubiscoto $\mathrm{RE}$ is small. The relative role of photorespiration is likely to be lower in OF which contains a small 
proportion of C4 plants (Novick et al., 2004). Our goal was not to quantify differences between GEP and GPP or to attempt to quantify the photorespiratory term in ECmeasured RE. Rather, our criteria for success in employing an ideal FPM is its ability to estimate GEP, $\mathrm{RE}$, and NEE values that are consistent with the mean and interannual variability determined by $\mathrm{C}$ flux estimates that are independent of eddy covariance, or based on models that assimilate multiple data sources.

We restrict our analysis of FPMs to those that have a basis in ecosystem physiology, namely those that parameterize known relationships between RE and temperature or between GEP (or NEE) and light. These methodologies employ the basic equations used by many ecosystem models, and thus can generate transferable information (e.g., terms of their parameters) for future studies of $\mathrm{C}$ dynamics both across time at the ecosystems studied here, and across space with respect to ecosystems with similar characteristics. To this end, we do not explore statistical methods such as multiple imputation (Hui et al., 2004) or more complex algorithms such as neural networks (Hagen et al., 2006), whose 'black-box' nature can complicate the analysis of relationships between driving variables and flux. Commonly used 'look-up tables' do not provide a formal mechanism for generating error estimates - as explored for the case of PP by Oren et al. (2006) - and are likewise not investigated here. After choosing the ideal FPM, we provide error estimates for all flux terms for each ecosystem-year of measurement.

\section{Methods}

\subsection{Site description}

Ecological characteristics of the study sites have been described extensively (Ellsworth et al., 1995; Oren et al., 1998; Lai and Katul, 2000; Pataki and Oren, 2003;
Novick et al., 2004). Briefly, OF is dominated by the grass Festuca arundinacea Shreb., with contributions from other $\mathrm{C} 3$ and $\mathrm{C} 4$ grasses and various herbs, and is mowed at least once annually for forage (Novick et al., 2004). PP is a 22-year-old (in 2005) planted Pinus taeda L. forest (Ellsworth et al., 1995; Oren et al., 1998; Katul et al., 1999). HW is an 80-100-year-old mixed deciduous forest dominated by late-successional shade-tolerant Quercus (oak) and Carya (hickory) species with fewer shade-intolerant individuals of Liquidambar styraciflua L. and Liriodendron tulipifera L. positioned in the upper canopy (Pataki and Oren, 2003; Palmroth et al., 2005).

Measurement details are listed in Table 2. Flux measurements were made with open path LI-7500 IRGAs (Li-Cor, Lincoln, NE) coupled with CSAT-3 sonic anemometers (Campbell Scientific, Logan, UT). A closed path system with a LI-6400 was employed at PP before 1 May 2001. Corrections to fluxes measured by the closed path system that resulted from an experiment with both open and closed path systems are described in Oren et al. (2006).

\subsection{Measurement period}

The 2001-2005 measurement period was notable for an extended drought that began in the latter part of the growing season (April-September) in 2001 (hereafter 'mild drought') and continued through most of the 2002 growing season ('severe drought', Table 3). Mean $T_{\mathrm{a}}$ was higher during the severe drought than during the other growing seasons measured here. A severe ice storm event in December 2002 sharply reduced leaf area index (LAI) at PP (McCarthy et al., 2006), but resulted in little observed damage to canopy structure and canopy conductance at OF and HW (Stoy et al., 2006). The 2003 growing season was wetter than average ('wet year') and the 2004 growing season experienced

Table 2

Summary of ancillary measurements and sensor locations

\begin{tabular}{|c|c|c|c|c|c|}
\hline \multirow[t]{2}{*}{ Variable } & \multirow[t]{2}{*}{ Instrument } & \multirow[t]{2}{*}{ Company } & \multicolumn{3}{|c|}{ Height $(\mathrm{m})$} \\
\hline & & & $\mathrm{OF}$ & PP & HW \\
\hline$T_{\mathrm{a}} / \mathrm{RH} / D$ & HMP $35 \mathrm{C} / 45 \mathrm{C}$ & Campbell Scientific, Logan, UT & 2.0 & 12 & 23 \\
\hline PAR & LI-190SA & Li-Cor, Lincoln, NE & 4.8 & 22.2 & 41.8 \\
\hline$R_{\mathrm{n}}$ & $\mathrm{Q}^{\mathrm{a}}, \mathrm{CNR} 1$ & REBS, Seattle, WA; Kipp and Zonen, Delft, The Netherlands & 4.8 & 22.2 & 41.8 \\
\hline$u / u_{*}$ & CSAT3 triaxial sonic anemometer & Campbell Scientific, Logan, UT & 2.8 & 20.2 & 39.8 \\
\hline LAI & LAI-2000, litter baskets & Li-Cor, Lincoln, NE & & & \\
\hline NEE/LE & LI $7500^{\mathrm{b}}$ & Li-Cor, Lincoln, NE & 2.8 & 20.2 & 39.8 \\
\hline
\end{tabular}

Negative height values denote distance belowground.

${ }^{\text {a }}$ Q7 radiometers were employed before 1 January 2004 and the CNR1 radiometers thereafter.

b Coupled to CSAT3. Corrections for the effects of air density on flux measurements were calculated after Webb et al. (1980). 
Table 3

Interannual variation in the sum $(\Sigma)$ of precipitation $(P)$ and photosynthetically active radiation (PAR) and mean air temperature $\left(T_{\mathrm{a}}\right)$ during the April-September growing season (gs) across the 2001-2005 measurement period

\begin{tabular}{|c|c|c|c|c|}
\hline Year & $\sum P\left(\mathrm{~mm} \mathrm{gs}^{-1}\right)$ & Hydrologic signature & $\sum$ PAR (mol photons $\mathrm{m}^{-2} \mathrm{gs}^{-1}$ ) & Mean $T_{\mathrm{a}}\left({ }^{\circ} \mathrm{C}\right)$ \\
\hline 2001 & $529(-1 \sigma)$ & Mild late-season drought & 7274 & 20.3 \\
\hline 2002 & $371(-2 \sigma)$ & Severe drought & 7135 & 21.9 \\
\hline 2003 & $790(+1 \sigma)$ & Wet & 6472 & 20.4 \\
\hline 2004 & 661 & Normal & 6692 & 21.0 \\
\hline 2005 & $359(-2 \sigma)$ & Severe late-season drought & 6669 & 21.2 \\
\hline
\end{tabular}

Numbers in parentheses are the standard deviation $(\sigma)$ of the measurements from the long-term (110 years) mean. Monthly climatic and hydrologic variability for the 2001-2004 period is detailed in Stoy et al. (2006).

precipitation $(P)$ commensurate with the long-term (110 years) mean ('average year'). $P$ during the 2005 growing season was extremely low as in 2002, but the effects of this drought were constrained to the latter months as in 2001. The cloudier conditions during the 2003-2005 growing seasons resulted in lower photosynthetically active radiation (PAR) than during the previous years (Table 3). Macroclimatic conditions were identical among ecosystems because they are adjacent; flux towers lie within $750 \mathrm{~m}$ of each other. Some micrometeorological drivers, including vapor pressure deficit $(D)$, soil temperature $\left(T_{\mathrm{s}}\right)$ and $\theta$, varied slightly among ecosystems and across seasons due to inter-ecosystem differences in LAI and evapotranspiration (Stoy et al., 2006).

\subsection{Flux partitioning methods}

We explored four methods of varying complexity to partition NEE into its RE and GEP components. We restricted our analysis to methods that parameterize known relationships between meteorological driving variables and flux to maximize information transfer with modeling efforts as mentioned. Two methods, one based on the annual $\mathrm{Q}_{10}$ model (AQ10) and another on short-term exponential fits (STE), use measured nighttime fluxes (defined here as periods in which the solar zenith angle exceeds $90^{\circ}$ ) to model RE as a function of temperature. The other two methods, one based on the rectangular hyperbolic fit (RH) and the other on a nonrectangular hyperbolic fit (NRH), use the intercept of the relationship between PAR and daytime $\mathrm{NEE}\left(\mathrm{NEE}_{\mathrm{d}}\right)$ to model RE. GEP was then calculated by definition:

$$
\mathrm{GEP}=\mathrm{NEE}-\mathrm{RE}
$$

We use the micrometeorological convention where fluxes from biosphere to atmosphere are denoted as positive. The NRH was used to gap-fill missing $\mathrm{NEE}_{\mathrm{d}}$ measurements for the AQ10 and STE; these methods as employed here only gap-fill nighttime RE measure- ments, a far larger source of missing EC data. All model parameters were determined using non-linear least squares via an unconstrained Gauss-Newton algorithm (MATLAB, Natick, MA). Optimization via the Levenburg-Marquardt algorithm was also investigated but did not result in substantial differences in annual flux estimates. We note that the error distribution of EC measurements may be better approximated as double exponential (Laplacian), rather than normal (Gaussian), and thus least absolute regression may be preferred for estimating model parameters (Hollinger and Richardson, 2005; Richardson and Hollinger, 2005; Richardson et al., 2006). We employed least-squares optimization here for comparisons with previous studies.

\subsection{Anпual $Q_{10}(A Q 10)$}

One of the simplest methods for gap-filling missing nighttime data is to model RE measurements collected under nighttime conditions of sufficient turbulence (e.g., $u_{*}>0.2 \mathrm{~m} \mathrm{~s}^{-1}$, Fig. 1) as a function of a physical driver, usually $T_{\mathrm{a}}$ or $T_{\mathrm{s}}$, or to use a slightly more complex model that might include, for example, $\theta$. Morgenstern et al. (2004) found 29 studies between 1993 and 2001 that employed different methods to relate RE to $T$. Here, we use the commonly employed $Q_{10}$ model:

$\mathrm{RE}_{\mathrm{AQ} 10}=R_{10} Q_{10}^{\left(T_{\mathrm{a}}-10\right) / 10}$

where $R_{10}$ is base RE at a reference temperature, here $10{ }^{\circ} \mathrm{C}$, and $Q_{10}$ describes the exponential temperature response of RE. At both PP and HW, the frequency characteristics of RE estimated from Eq. (2) better matched the frequency characteristics of observed RE when $T_{\mathrm{a}}$ rather than $T_{\mathrm{s}}$ was used as the driving variable (Stoy et al., 2005). The parameter values of $R_{10}$ and $Q_{10}$ were determined for each ecosystem at the annual time scale. Seasonal variations in $u *$ are likely to result in a data set that is biased towards colder periods when 
parameterizing Eq. (2) (Gu et al., 2005; Reichstein et al., 2005). This is in part attributable to the fact that summer-time nocturnal runs experience smaller mean $u *$ than their winter-counterpart at these ecosystems (see Juang et al., 2006 or Stoy et al., 2006 for time series of $u_{*}$ measurements at the study sites).

\subsection{Short-term exponential (STE)}

Reichstein et al. (2005) noted that the parameters in Eq. (2) may vary along the annual cycle (cf. Janssens and Pilegaard, 2003; Palmroth et al., 2005) and suggested a strategy by which the parameter values of the base respiration and the temperature response can be estimated over the time scales at which they might vary using the 'short-term exponential' (STE) method. They used the Arrhenius (1889) equation after Lloyd and Taylor (1994):

$\mathrm{RE}_{\mathrm{STE}}=R_{10, \mathrm{STE}} \exp \left(E_{0}\left[\frac{1}{283.15-T_{0}}-\frac{1}{T_{\mathrm{a}}-T_{0}}\right]\right)$

with a constant $T_{0}$ parameter $(227.13 \mathrm{~K}$, Lloyd and Taylor, 1994) and a 15-day moving window to determine variability in the temperature sensitivity parameter $\left(E_{0}\right)$, then a 4-day window to estimate the base respiration parameter $\left(R_{10, \mathrm{STE}}\right)$. More methodological details are discussed in Reichstein et al. (2005).

\subsection{Rectangular hyperbola $(R H)$}

Lee et al. (1999) noted that the relationship between accepted nighttime flux data and $T$ was statistically significant but considerably scattered. To investigate the seasonal dynamics of RE in a way that was less subject to the constraints of nighttime EC data quality, they used the intercept parameter $(\gamma)$ of the rectangular hyperbolic model (RH, i.e., the Michaelis-Menten model), which for NEE can be written as (Ruimy et al., 1995):

$\mathrm{NEE}_{\mathrm{RH}}=-\frac{\alpha \beta \mathrm{PAR}}{\alpha \mathrm{PAR}+\beta}+\gamma$

where $\alpha$ is the mean apparent ecosystem quantum yield, $\beta$ is GEP at light saturation, and signs follow the micrometeorological convention. Lee et al. (1999) used a 15-day window to estimate the parameters in Eq. (4), and then regressed $\gamma$, as a measure of RE, against $T_{\mathrm{s}}$. We determined the parameters of Eq. (4) for monthly periods because some gaps in the 15 site-year measure- ment period were greater than 15 days, and used monthly $\gamma$ as an estimate of RE.

\subsection{Non-rectangular hyperbola $(\mathrm{NRH})$}

Gilmanov et al. (2003) proposed a method that employs a non-rectangular hyperbolic fit (NRH):

$$
\begin{aligned}
\mathrm{NEE}_{\mathrm{NRH}}= & -\frac{1}{2 \eta}(\alpha \mathrm{PAR}+\beta \\
& -\sqrt{\left.(\alpha \mathrm{PAR}+\beta)^{2}-4 \alpha \beta \eta \mathrm{PAR}\right)}+\gamma
\end{aligned}
$$

where $\alpha, \beta$ and $\gamma$ have the same definition as in Eq. (4), and the parameter $\eta$ describes model curvature as the NEE/PAR relationship approaches saturation. Eq. (4) is a special case of Eq. (5) when $\eta=1$. A major methodological difference between the NRH and the $\mathrm{RH}$ methods is that in the NRH, parameters were estimated for daily periods according to the original use of Eqs. (4) and (5) (Gilmanov et al., 2003), and missing data were gap-filled using Eq. (5) with mean monthly parameter values in the former. Because an unconstrained nonlinear optimization was performed, daily parameter sets were rejected if parameter values were not realistic (i.e., if $\alpha, \gamma$ or $\eta$ were less than zero and if $\eta$ was greater than unity), or if the root mean squared error between model and measurements exceeded $0.001 \mathrm{mg} \mathrm{C} \mathrm{m}^{-2} \mathrm{~s}^{-1}$. Parameter sets were also rejected in instances where the Gauss-Newton algorithm did not converge to a solution within the specified tolerance (here $10^{-6}$ ) within the maximum admissible number of iterations (here 4000). In these cases, the four-parameter NRH model was a poor descriptor of the data for that day of the measurement record.

\subsection{Thresholds}

FPM parameters, and thus annual NEE estimates, may be sensitive to extreme data values. An added advantage of the NRH is that it can recursively provide inference into realistic flux data thresholds that otherwise might have to be selected subjectively, because extreme values may result in non-convergence of the curve-fitting algorithm on a daily basis. We explored the population of data points from daily data sets when the GaussNewton algorithm converged to an optimum and determined the minimum admissible NEE measurement to be $-0.7,-0.85$, and $-0.8 \mathrm{mg} \mathrm{C} \mathrm{m}^{-2} \mathrm{~s}^{-1}$ for $\mathrm{OF}, \mathrm{PP}$, and $\mathrm{HW}$, respectively, and the maximum NEE threshold to be $0.5 \mathrm{mg} \mathrm{C} \mathrm{m}^{-2} \mathrm{~s}^{-1}$ for all ecosystems. Measurements that exceeded these thresholds were removed. The maximum NEE threshold is larger than the maximum 
soil respiratory fluxes reported in Palmroth et al. (2005) for PP and HW, as expected for whole ecosystem respiration.

To minimize subjectivity in determining a $u_{*}$ threshold to filter nighttime data (Barford et al., 2001), we used the atmospheric stability threshold after Novick et al. (2004), which requires near-neutral atmospheric stability for nighttime data acceptance. There are three reasons for adopting this threshold: (1) Day-time and night-time footprint sizes become comparable (though not identical). This is an important consideration if footprint size may exceed ecosystem dimensions, as is the case here, or if there is a large spatial component in ecosystem flux activity, as discussed for the case of PP by Oren et al. (2006). (2) The flux-transporting eddies under near-neutral conditions are dominated by ramp-like structures that appear insensitive to rapid transients such as passage of clouds during nocturnal conditions (Cava et al., 2004). (3) Storage fluxes are likely to be small under near-neutral conditions when compared to the fluxes above the canopy (Juang et al., 2006). We note that $u *$ thresholds are employed in the original usage of the STE. These thresholds are determined over 3-month periods for each ecosystem based on the original algorithm described in Reichstein et al. (2005). Briefly, flux data are sorted into temperature and $u_{*}$ classes and the threshold for each class is taken to be the $u *$ value for which mean flux exceeded $95 \%$ of the mean flux at higher values of $u *$. Because the intent of this method is similar to one of the goals of the atmospheric stability method - to make flux estimates independent of turbulent statistics - we adopted the atmospheric stability threshold for the STE as well.

\subsection{Information content}

In addition to the comparison among FPMs, we explored the information content (IC) of raw and gapfilled flux data in both the probability and frequency domains using the Shannon entropy and a wavelet variant thereof. We undertook this analysis to investigate how the process of gap-filling generates differences in the IC relative to that contained in raw data (Katul et al., 2001a). The Shannon-entropy $\left(\mathrm{ENT}_{\mathrm{S}}\right.$; Shannon, 1948) is a formal method for assessing the IC and is calculated as

$\mathrm{ENT}_{\mathrm{S}}=-\sum_{i}^{N} p_{i}(\hat{x}) \ln \left(p_{i}(\hat{x})\right)$ where $p_{i}$ is the discrete probability density function (here estimated from a histogram defined over $N$ bins) of an arbitrary time series having zero mean and unit variance, i.e., if $x$ denotes the original time series, then $\hat{x}=(x-\bar{x}) / \sigma_{x}$ where the over bar denotes time averaging and $\sigma=\left(\overline{(x-\bar{x})^{2}}\right)^{1 / 2}$ is the standard deviation. Maximum entropy (or minimum IC) is attained when $p_{i}=1 / N$, which represents random (white) noise. We further normalized our entropy estimates by this maximum theoretical value such that when $p_{i}=1 / \mathrm{N}$, $\mathrm{ENT}_{\mathrm{S}}=1$. This normalization provides entropy estimates that are independent of $N$ provided $N$ is sufficiently large (here 200).

$\mathrm{ENT}_{\mathrm{S}}$ integrates the IC over time through the pdf and hence is primarily sensitive to the frequency of occurrence of excursions in NEE measurements from their mean state. To quantify whether gap-filling results in a change in the frequency characteristics of NEE (or alternatively their auto-correlation), we computed the 'wavelet entropy' $\left(\mathrm{ENT}_{\mathrm{W}}\right)$ of normalized raw and gapfilled flux time series after computing orthonormal wavelet coefficients using the Haar wavelet basis. In this application, $p$ (Eq. (6)) represents the spectral energy of the Haar wavelet coefficients computed over a sequential doubling of frequencies $i$ and $N=\log _{2}(87648)-1 \cong 15$, where 87,648 is the number of $1 / 2 \mathrm{~h}$ periods in the 5 -year measurement records. Note that because of the strong locality of the Haar wavelet basis in the temporal domain, $p$ can be readily computed for both gap-filled and gap-infected time series. More details on the application of the wavelet transformation for flux analysis can be found elsewhere (Katul et al., 2001b; Braswell et al., 2005; Stoy et al., 2005).

\section{Results and discussion}

\subsection{Flux partitioning methods}

The salient results of the FPM analyses (Fig. 2) are that (1) flux estimation is highly sensitive to the method employed, and (2) the simpler methodologies return unrealistically high interannual mean flux magnitude (the $\mathrm{AQ} 10$ and $\mathrm{RH}$ ) or variation in flux (AQ10). For example, mean $\mathrm{NEE}_{\mathrm{RH}}$ at $\mathrm{HW}$ is less than $-700 \mathrm{~g} \mathrm{C} \mathrm{m}^{-2}$ year $^{-1}$ (Fig. 2A), a stronger $\mathrm{C}$ sequestration rate than predicted by all methods for all ecosystems, even the fast-growing $\mathrm{PP}$. In contrast, the AQ10 predicts that $\mathrm{OF}$ is a $\mathrm{C}$ source of $400 \mathrm{~g} \mathrm{C} \mathrm{m}^{-2}$ year $^{-1}$ on average, a situation that would not be sustainable over the long term. Also, the interannual variability of $\mathrm{NEE}_{\mathrm{AQ} 10}$ is higher by over 

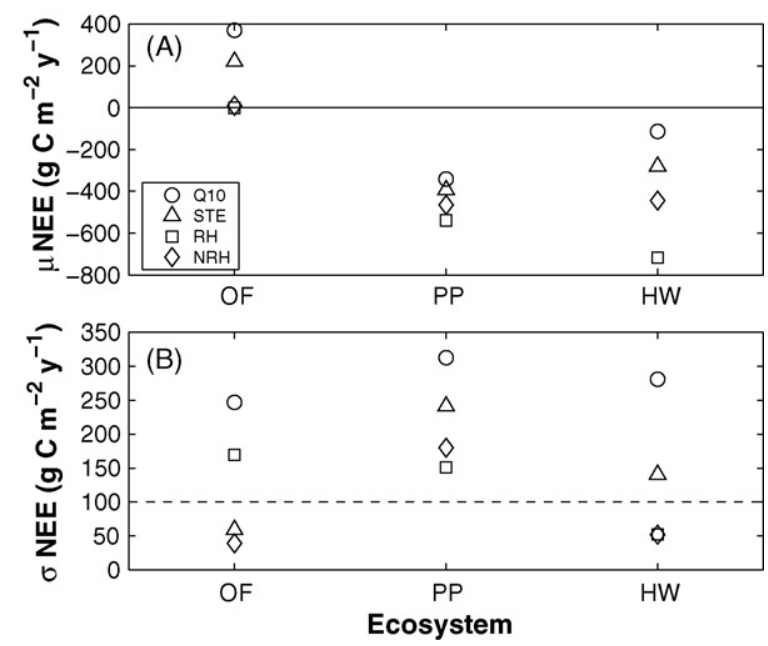

Fig. 2. The mean (A) and standard deviation (B) of annual NEE at old field (OF), planted pine (PP) and hardwood forest (HW) ecosystems for the 2001-2005 measurement period. Negative values represent flux from atmosphere to biosphere. A comprehensive spatial variability study combined with a flux error analysis by Oren et al. (2006) suggested that NEE error at PP is on the order of $100 \mathrm{~g} \mathrm{C} \mathrm{m}^{-2} \mathrm{year}^{-1}$, as indicated by the dashed line.

$50 \mathrm{~g} \mathrm{C} \mathrm{m}^{-2}$ year $^{-1}$ for all ecosystems, in part because it results in unreasonable values for certain ecosystemyears (Appendix B). For example, observe the strong C source predicted for PP in 2002, and the positive NEE estimates at HW during the drought years of 2001 and 2002 but negative estimates during the drought year of 2005 (see Appendix B). We, therefore, concentrate on the contrast between the STE and the NRH, both of which generated more realistic estimates of NEE, RE, and GEP (Fig. 2, Table 4). (Flux estimates for each site year generated by the AQ10 and RH methods are listed in Table B1 for completeness.) We note that minor differences in the output of two different techniques is expected and may fall within the range of error quantified in the case of NEE at PP to be over $100 \mathrm{~g} \mathrm{C} \mathrm{m}^{-2}$ year $^{-1}$ for some years (Oren et al., 2006), as indicated by the dashed line in Fig. 2. Therefore, we interpret the results from periods in which estimates differed from expectations by at least that amount. We begin with the STE method and discuss only the major findings of the comparisons.

The STE estimated that OF lost nearly $1100 \mathrm{~g} \mathrm{C} \mathrm{m}^{-2}$ year $^{-1}$ (Table 4A) to the atmosphere over the measurement period, a value that is difficult to reconcile with the amount of $\mathrm{C}$ removed as biomass during the annual mow, which represented an additional loss of ca. 100, 100, 400, 200 and $100 \mathrm{~g} \mathrm{C} \mathrm{m}^{-2}$ year $^{-1}$ for 2001-2005, respectively. Despite anomalous $\mathrm{NEE}_{\mathrm{STE}}$ values at $\mathrm{OF}$, annual $\mathrm{GEP}_{\mathrm{STE}}$ was strongly
Table 4

Estimates of net ecosystem exchange (NEE), ecosystem respiration (RE), and gross ecosystem productivity (GEP) in old field (OF), pine plantation (PP) and hardwood forest (HW) ecosystems from (A) the short-time exponential method (STE) of Reichstein et al. (2005) and (B) the non-rectangular hyperbolic (NRH) method of Gilmanov et al. (2003)

\begin{tabular}{|c|c|c|c|c|}
\hline Ecosystem & Year & NEE & GEP & $\mathrm{RE}$ \\
\hline \multicolumn{5}{|l|}{ (A) STE } \\
\hline \multirow[t]{5}{*}{ OF } & 2001 & 200 & -1720 & 1920 \\
\hline & 2002 & 200 & -1270 & 1470 \\
\hline & 2003 & 320 & -2170 & 2490 \\
\hline & 2004 & 200 & -1770 & 1980 \\
\hline & 2005 & 170 & -1310 & 1480 \\
\hline \multirow[t]{5}{*}{ PP } & 2001 & -360 & -2410 & 2050 \\
\hline & 2002 & 20 & -2440 & 2460 \\
\hline & 2003 & -220 & -2080 & 1860 \\
\hline & 2004 & -520 & -2190 & 1670 \\
\hline & 2005 & -770 & -2690 & 1920 \\
\hline \multirow[t]{5}{*}{ HW } & 2001 & -230 & -2240 & 2000 \\
\hline & 2002 & -100 & -2220 & 2120 \\
\hline & 2003 & -240 & -1980 & 1740 \\
\hline & 2004 & -350 & -2000 & 1650 \\
\hline & 2005 & -470 & -1850 & 1380 \\
\hline \multicolumn{5}{|l|}{ (B) $\mathrm{NRH}$} \\
\hline \multirow[t]{5}{*}{$\mathrm{OF}$} & 2001 & -40 & -1270 & 1230 \\
\hline & 2002 & 20 & -970 & 980 \\
\hline & 2003 & -30 & -1520 & 1500 \\
\hline & 2004 & 30 & -1360 & 1390 \\
\hline & 2005 & 60 & -1050 & 1110 \\
\hline \multirow[t]{5}{*}{$\mathrm{PP}$} & 2001 & -610 & -1950 & 1340 \\
\hline & 2002 & -270 & -1880 & 1610 \\
\hline & 2003 & -230 & -1950 & 1730 \\
\hline & 2004 & -420 & -2180 & 1760 \\
\hline & 2005 & -740 & -2580 & 1840 \\
\hline \multirow[t]{5}{*}{ HW } & 2001 & -510 & -1710 & 1200 \\
\hline & 2002 & -390 & -1710 & 1320 \\
\hline & 2003 & $-170(-400)$ & $-1610(-1650)$ & 1440 (1250) \\
\hline & 2004 & -430 & -1750 & 1310 \\
\hline & 2005 & -490 & -1720 & 1230 \\
\hline
\end{tabular}

Numbers in parentheses represent adjusted estimates of 2003 HW fluxes after accounting for clear-cut effects using the footprint thresholding methodology described in Appendix A. Units are $\mathrm{g} \mathrm{C} \mathrm{m}^{-2}$ year $^{-1}$. NEE estimates using the NRH for the 2001-2004 period for PP were given in Oren et al. (2006). They are reproduced here for completeness.

related to ET ( $r^{2}=0.78$, Stoy et al., 2006), as expected due to the coupling of these two fluxes via stomatal function.

$\mathrm{NEE}_{\mathrm{STE}}$ at PP followed an interannual pattern that was broadly consistent with the drought sensitivity of $P$. taeda and the $P$ record during the 5-year study period (Oren et al., 1998; Pataki and Oren, 2003; Stoy et al., 2005; Stoy et al., 2006), and the ice storm-induced reduction in LAI (McCarthy et al., 2006). GEP STE $_{\text {S }}$ 
ranged from ca. 2000 to $2700 \mathrm{~g} \mathrm{C} \mathrm{m}^{-2}$ year $^{-1}$ (Table 4A) largely within the range predicted by the independent estimates $\left(1800-2500 \mathrm{~g} \mathrm{C} \mathrm{m}^{-2}\right.$ year $^{-1}$, Table 1). However, NEE $\mathrm{NTE}_{\text {was }}$ positive in 2002 and $\mathrm{RE}_{\mathrm{STE}}$ during 2003 was $600 \mathrm{~g} \mathrm{C} \mathrm{m}^{-2}$ year $^{-1}$ less than during severe drought (2002) despite the substantial production of needle and branch litter by the ice storm, which is an unexpected result.

GEP $_{\text {STE }}$ differed by less than $20 \%$ among years at HW, as expected at a late successional hardwood forest comprised largely of drought-tolerant species (Pataki et al., 1998; Oren and Pataki, 2001; Pataki and Oren, 2003; Palmroth et al., 2005). However, $\mathrm{RE}_{\mathrm{STE}}$ differed by nearly $35 \%$ among years; the 2001 and $2002 \mathrm{RE}_{\mathrm{STE}}$ estimates were over $600 \mathrm{~g} \mathrm{C} \mathrm{m}^{-2}$ year $^{-1}$ greater than 2005 despite similar drought conditions. Consequently, the magnitude of $\mathrm{NEE}_{\mathrm{STE}}$ during 2005 was more than twice that in 2001 and nearly five times the 2002 estimate. In summary, whereas the STE largely agreed with expectations of ecosystem flux given prior knowledge, there were a number of instances where results may be considered unreasonable.

At $\mathrm{OF}$, mean annual $\mathrm{NEE}_{\mathrm{NRH}}$ was not significantly different from zero as determined by a two-tailed unequal variance $t$-test $(p=0.69, t=0.43 ;$ Ruxton, 2006). However, adding biomass removed by the mow to $\mathrm{NEE}_{\mathrm{NRH}}$ resulted in a distribution that is significantly different from zero ( $p=0.24, t=3.5)$ with a mean of ca. $-200 \mathrm{~g} \mathrm{C} \mathrm{m}^{-2}$ year $^{-1}$. This is the imbalance in the $\mathrm{C}$ budget that cannot be explained by combining EC and harvest estimates, and represents either measurement uncertainty or an annual loss of soil $\mathrm{C}$ to the atmosphere or to groundwater via dissolved organic carbon (DOC) dissolution. At PP, growing nearby on the same soil, DOC represents a trivial ecosystem $\mathrm{C}$ loss compared to other fluxes (ca. $10 \mathrm{~g} \mathrm{C} \mathrm{m}^{-2}$ year $^{-1}$, Schäfer et al., 2003). Other soil $\mathrm{C}$ losses can be inferred by comparison with PP because both ecosystems shared common management practices and ecosystem composition across a large portion of their current extents. Preliminary estimates of belowground $\mathrm{C}$ show similar values $\left(\sim 4500 \mathrm{~g} \mathrm{C} \mathrm{m}^{-2}, \mathrm{~K}\right.$. Johnsen, unpublished) at both sites. Thus, it is unlikely that soil $\mathrm{C}$ loss explains the imbalance, which appears to be attributable to measurement uncertainty. Whereas a lack of closure of $200 \mathrm{~g} \mathrm{C} \mathrm{m}^{-2}$ year $^{-1}$ appears large compared to the near zero NEE estimates, this term is within the range of error of $\mathrm{GEP}_{\mathrm{NRH}}$ and $\mathrm{RE}_{\mathrm{NRH}}$ as discussed below. The lack of closure that results from using NRH estimates is approximately half of that which arises when using the STE.

Annual $\mathrm{GEP}_{\mathrm{NRH}}$ at $\mathrm{OF}$ was strongly related to ET $\left(r^{2}=0.84\right)$, but averaged over $400 \mathrm{~g} \mathrm{C} \mathrm{m}^{-2}$ year $^{-1}$ less than $\mathrm{GEP}_{\mathrm{STE}}$ due to lower RE estimates. The 2001 GEP and RE estimates using the NRH and STE were on the order of -1300 and 1200 and -1700 and $1900 \mathrm{~g} \mathrm{C} \mathrm{m}^{-2}$ year $^{-1}$, respectively. The $\mathrm{GEP}_{\mathrm{NRH}}$ and $\mathrm{RE}_{\mathrm{NRH}}$ estimates for 2001 are closer to those of Novick et al. (2004), who used a combination of EC and porometry measurements in conjunction with a big leaf model to estimate GEP and RE values of -1200 and $1300 \mathrm{~g} \mathrm{C} \mathrm{m}^{-2}$ year $^{-1}$, respectively.

At PP, the magnitude of $\mathrm{NEE}_{\mathrm{NRH}}$ was largest in the years with late-season droughts, 2001 and 2005. Although at first glance this appears puzzling, the finding is reasonable when considering that in both years growing conditions were ideal until the latter part of the growing season when the drought intensified; Palmroth et al. (2005) demonstrated that in both stands low $\theta$ greatly reduced soil respiration. Thus, high NEE in these years is due to high GEP early in the season followed by low RE later in the season. $\mathrm{GEP}_{\mathrm{NRH}}$ and $\mathrm{RE}_{\mathrm{NRH}}$ for PP were slightly larger in magnitude than estimates for an earlier period (1998-1999) obtained with an inverse modeling approach (Lai et al., 2002, Tables 1 and 4B), consistent with the fact that the PP canopy closed only at the end of 1999 . $\mathrm{GEP}_{\mathrm{NRH}}$ and $\mathrm{RE}_{\mathrm{NRH}}$ for 2001-2003 at PP were approximately equal to or slightly lower than estimates from a similar inversion approach that accounted for local thermal stratification (Juang et al., 2006). GEP is expected to be lower than GPP due to the C 'recycling' issues mentioned in Section 1. GEP $\mathrm{NRH}_{\mathrm{NH}}$ was equal to or slightly lower than GPP from budgeting approaches (Hamilton et al., 2002) and estimates based on sap flux constraints (Schäfer et al., 2003), with a similar degree of interannual variability (Tables 1 and 4). $\mathrm{NEE}_{\mathrm{NRH}}$ at PP was lowest in $2003\left(-225 \mathrm{~g} \mathrm{C} \mathrm{m}^{-2}\right.$ year $\left.^{-1}\right)$, as expected after ice storm canopy damage, but its magnitude was over $200 \mathrm{~g} \mathrm{C} \mathrm{m}^{-2}$ year $^{-1}$ less than estimates from Juang et al. (2006).

Excluding 2003, interannual variability of $\mathrm{NEE}_{\mathrm{NRH}}$, $\mathrm{GEP}_{\mathrm{NRH}}$, and $\mathrm{RE}_{\mathrm{NRH}}$ at $\mathrm{HW}$ were low, on the order of 50-100 $\mathrm{g} \mathrm{C} \mathrm{m}^{-2}$ year $^{-1}$. A two-dimensional footprint analysis suggests that fluxes during 2003 were impacted by the December 2002 private land clear-cut (see Appendix A). After accounting for the clear-cut effects, HW had the lowest NEE variability among the methods for all three ecosystems, as expected based on results from previous sap flux and soil respiration studies (Pataki and Oren, 2003; Palmroth et al., 2005). This low interannual flux variability at HW is consistent with recent findings from a HW site at Walker Branch, TN by Hanson et al. (2004), who also found NEE variability on the order of $100 \mathrm{~g} \mathrm{C} \mathrm{m}^{-2}$ year $^{-1}$ for 1993-2000. These 


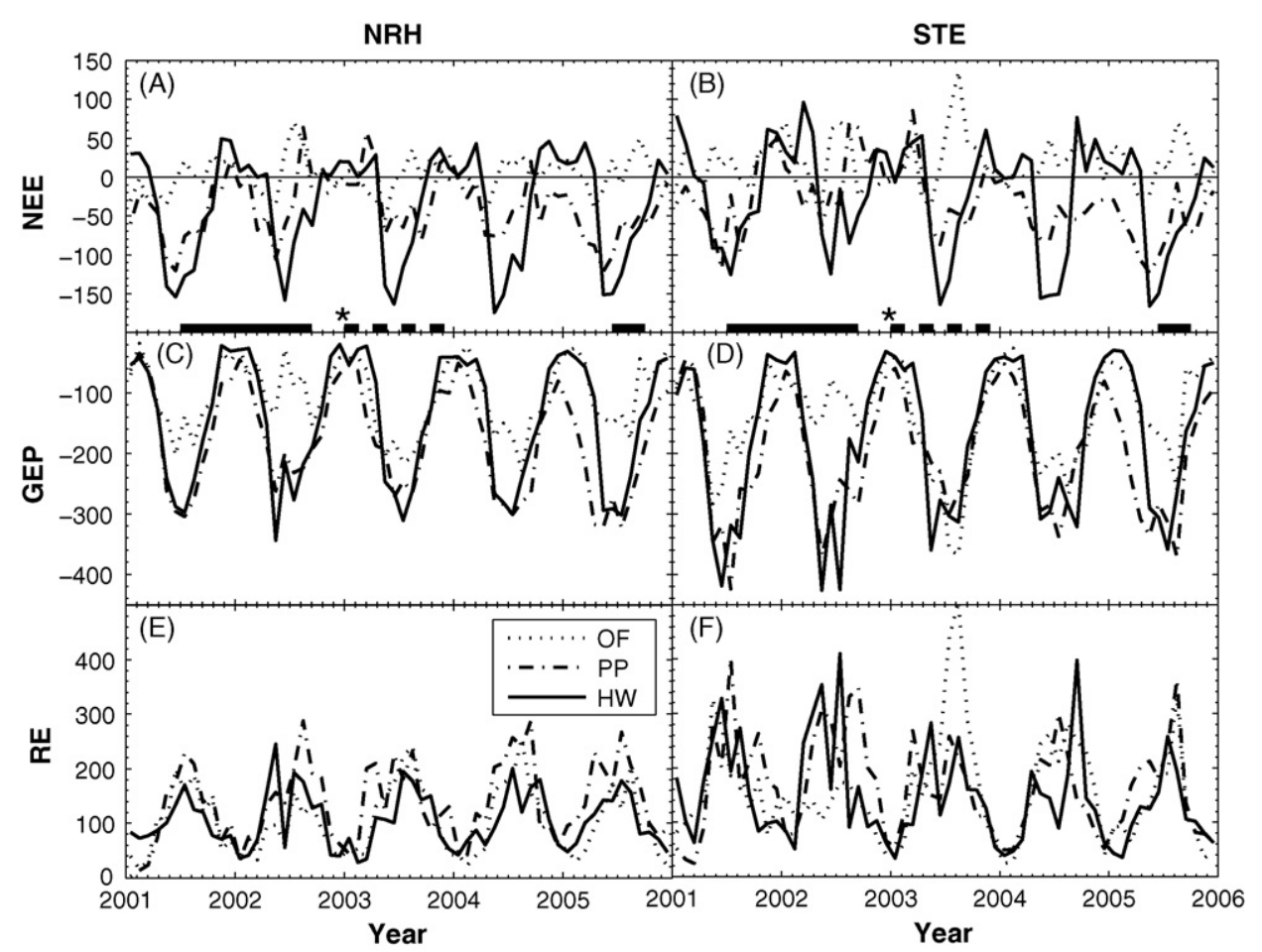

Fig. 3. Monthly net ecosystem exchange (NEE), gross ecosystem productivity (GEP) and ecosystem respiration (RE) at the old field (OF), planted pine (PP) and hardwood forest (HW) ecosystems in Duke Forest. NRH refers to estimates using the non-rectangular hyperbolic method of Gilmanov et al. (2003) and STE to estimates using the short-time exponential method of Reichstein et al. (2005). Drought and wet conditions are indicated by solid and dashed bars, respectively. The severe ice storm in December 2002 is indicated by an asterisk. Flux units are ${\mathrm{g} \mathrm{C} \mathrm{m}^{-2} \mathrm{month}}^{-1}$.

values were gap-filled using the 'look-up table' method, incorporating a temperature response curve for $\mathrm{RE}$ similar to the AQ10; we showed earlier that such approach tends to amplify interannual variability. In summary, annual flux estimates using the NRH largely matched independent estimates with the possible exception of the low 2003 NEE estimate at PP. We proceed to compare monthly estimates from the STE and NRH approaches.

Monthly NEE, GEP, and RE estimates from the NRH and STE generally followed a logical seasonal pattern (Fig. 3) with the most notable deviation being the extremely high $\mathrm{RE}_{\mathrm{STE}}$ estimates during late summer in 2003 at OF. This period was marked with vigorous grass growth (Stoy et al., 2006), but a monthly respiratory flux of $500 \mathrm{~g} \mathrm{C} \mathrm{m}^{-2}$ month $^{-1}$ seems unlikely and exceeds many of the annual RE estimates for grassland ecosystems worldwide as summarized in Novick et al. (2004). The dramatic decrease in GEP at OF during the peak of the 2002 drought is also apparent in both methods. Grasses were largely dead during this period. Interestingly, both methods predict that $\mathrm{PP}$ is a $\mathrm{C}$ sink during the winter between 2004 and 2005 as ice storm recovery was nearing completion, but wintertime NEE was slightly positive or near zero on a monthly basis during other years. HW exhibits later leaf-on phenology than the other two ecosystems (one of which is coniferous), and this effect can be observed in the GEP dynamics of both methods. Finally, the STE estimates show a decline in peak monthly GEP and RE through time at PP and HW (Fig. 3); the magnitude of maximum monthly component fluxes is higher in 2001 and 2002 than in 2003 and 2004 excluding a spike in $\mathrm{RE}_{\mathrm{STE}}$ at HW in late 2004. This result is difficult to reconcile with the fact that the 2001 and 2002 period experienced drought; the pattern is inconsistent with estimates based on the NRH approach.

\subsection{Information content}

The IC of gap-filled $\mathrm{NEE}_{\mathrm{d}}$ was similar to the IC in the gap-infested time series in both the Shannon entropy $\left(\mathrm{ENT}_{\mathrm{S}}\right)$ and wavelet entropy $\left(\mathrm{ENT}_{\mathrm{W}}\right)$ sense; raw and gap-filled $\mathrm{NEE}_{\mathrm{d}}$ data differed by a maximum of 2 and $7 \%$ for $\mathrm{ENT}_{\mathrm{S}}$ and $\mathrm{ENT}_{\mathrm{W}}$, respectively (Table 5, note that ENT as defined here exists between 0 and 1). Gap-filled 
Table 5

The Shannon entropy $\left(\mathrm{ENT}_{\mathrm{S}}\right)$ and wavelet entropy $\left(\mathrm{ENT}_{\mathrm{W}}\right)$ values for daytime net ecosystem exchange $\left(\mathrm{NEE}_{\mathrm{d}}\right)$ and ecosystem respiration (RE) for the 2001-2005 measurement period at the old field (OF), pine plantation (PP) and hardwood forest (HW) study ecosystems

\begin{tabular}{llll}
\hline $\mathrm{NEE}_{\mathrm{d}}$ & Ecosystem & Raw data & Gap-filled data \\
\hline $\mathrm{ENT}_{\mathrm{S}}$ & OF & 0.72 & 0.71 \\
& PP & 0.81 & 0.80 \\
& HW & 0.80 & 0.78 \\
$\mathrm{ENT}_{\mathrm{W}}$ & OF & 0.27 & 0.33 \\
& PP & 0.41 & 0.39 \\
& HW & 0.33 & 0.26
\end{tabular}

\begin{tabular}{lllll} 
RE & Ecosystem & Raw data & Gap-filled STE & Gap-filled NRH \\
\hline ENT $_{\text {S }}$ & OF & 0.66 & 0.74 & 0.51 \\
& PP & 0.73 & 0.74 & 0.54 \\
& HW & 0.60 & 0.73 & 0.46 \\
ENT $_{W}$ & OF & 0.55 & 0.29 & 0.32 \\
& PP & 0.28 & 0.28 & 0.27 \\
& HW & 0.38 & 0.41 & 0.39 \\
\hline
\end{tabular}

Raw data refers to eddy covariance data filtered using the atmospheric stability thresholding approach of Novick et al. (2004). NRH refers to nighttime data gap-filled using the non-rectangular hyperbola after Gilmanov et al. (2003) and STE refers to the short-term exponential approach of Reichstein et al. (2005). Missing $\mathrm{NEE}_{\mathrm{d}}$ data was gap-filled using the NRH. All entropy estimates are normalized by the maximum theoretical value.

data closely matched the frequency characteristics of the total NEE time series for all ecosystems (Fig. 4) with the exception of the higher frequencies, those on the time scale of hours on the left hand side of the abscissa in Fig. 4. This result was expected given the known spatial distribution of ecosystem activity (Oren et al., 2006). The FPMs did not seek to capture the scale of variability due to hourly shifts in footprint direction and extent because we focused on examining the longerterm estimates more relevant to the ecosystem $\mathrm{C}$ cycling questions referred to in the introduction. Therefore, gap-filling does not inject new information to the complete NEE time series in the probability domain, and in the spectral domains at time scales longer than approximately 1 day. Despite success in replicating the time domain and frequency characteristics of measured NEE data, the special case of nighttime NEE data (i.e., $\mathrm{RE}$ ) is a focus of the present study and warrants more investigation.

The $\mathrm{ENT}_{\mathrm{S}}$ of NRH-gap-filled RE was on average $16 \%$ lower than that of raw nighttime flux data, and the ENT $_{S}$ of STE-gap-filled data averaged $23 \%$ higher than $\mathrm{RE}_{\mathrm{NRH}}$ (Table 5). From this analysis, it is clear that gapfilling using the NRH adds 'organization' to the pdf of nighttime NEE, and that $\mathrm{RE}_{\mathrm{STE}}$ is more random than its
NRH counterpart. This result follows from the fact that the NRH models RE as a constant that varies monthly and the STE models RE as an exponential function of $T_{\mathrm{a}}$, itself highly variable on diurnal and seasonal time scales.

In contrast to the $\mathrm{ENT}_{\mathrm{S}}$, both the NRH and STE decreased the $\mathrm{ENT}_{\mathrm{W}}$ of RE on average (Table 5). In other words, gap-filling RE adds order to (or filters out randomness of) the time series in the spectral domain. This spectral imbalance is unavoidable unless far more nighttime runs are accepted, which would reduce data quality. This result may not be surprising given the highly stochastic nature of nighttime EC flux measurements, as indicated by the relatively high degree of spectral energy on the hourly time scale (Fig. 4). At OF and HW the power spectra of nighttime data increase at high frequencies, and exhibit the characteristics of high frequency noise when compared to hourly flux data from the entire NEE time series. However, the direct comparison of flux magnitudes indicates that the magnitude of annual RE was similar to independent estimates, especially when using the NRH. For these reasons and those discussed above, the NRH is the preferable FPM for gap-filling NEE data in the case of these ecosystems. This finding agrees with the comparison of EC and inverse model estimates at PP (Juang et al., 2006) in which RE estimates based on the intercept of the light response curve compared well at the annual basis with RE estimates from a Eulerian version of a constrained source optimization inverse model (Lai et al., 2002).

\subsection{Flux error}

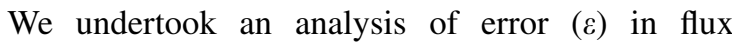
estimates generated by the NRH to provide a complete description of flux findings for the 2001-2005 period at the Duke Forest AmeriFlux ecosystems, noting that the largest component of flux $\varepsilon$ may be FPM selection itself (Hagen et al., 2006), which in part motivated this study. The choice of the NRH after comparison with independent and model estimates is intended to decrease this uncertainty in model selection.

A full analysis of random, instrument, and spatial $\varepsilon$ was provided for PP NEE data by Oren et al. (2006). We expand on this analysis by providing $\varepsilon$ estimates for annual NEE, GEP, and RE for all ecosystem-years of measurement using a variation of the approach of Goulden et al. (1997) as discussed in greater detail in Stoy et al. (2006) and Oren et al. (2006). Briefly, $\varepsilon$ in NEE and RE due to gap-filling ('sampling uncertainty') was estimated by randomly selecting NRH parameters 


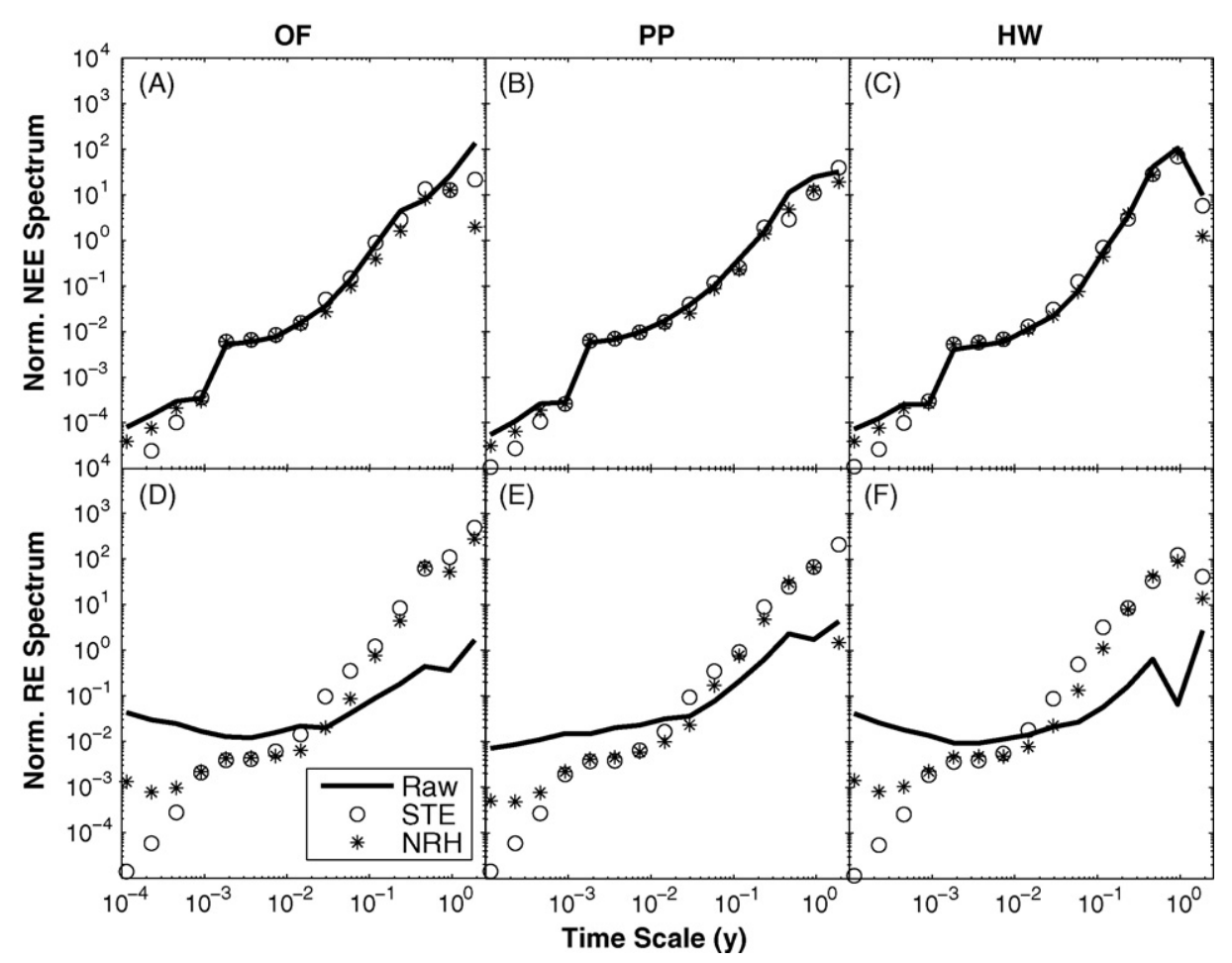

Fig. 4. Orthonormal wavelet spectra using the Haar wavelet basis for raw and gap-filled normalized (Norm.) net ecosystem exchange (NEE) and ecosystem respiration (RE) data for the Duke Forest old field (OF), pine plantation (PP) and hardwood forest (HW) ecosystems. STE and NRH refer to the short-term exponential gap-filling method of Reichstein et al. (2005) and the non-rectangular hyperbolic gap-filling method of Gilmanov et al. (2003), respectively.

Table 6

Error estimates for net ecosystem exchange (NEE), gross ecosystem productivity (GEP) and ecosystem respiration (RE) generated using the non-rectangular hyperbolic method (NRH) of Gilmanov et al. (2003)

\begin{tabular}{lccll}
\hline Ecosystem & Year & NEE & GEP & RE \\
\hline OF & 2001 & 68 & $274(22)$ & $265(21)$ \\
& 2002 & 48 & $290(30)$ & $286(29)$ \\
& 2003 & 49 & $241(16)$ & $236(16)$ \\
& 2004 & 42 & $253(19)$ & $249(18)$ \\
& 2005 & 48 & $177(17)$ & $170(15)$ \\
PP & 2001 & $92[108]$ & $188(11)$ & $165(13)$ \\
& 2002 & $100[111]$ & $235(16)$ & $214(19)$ \\
& 2003 & $96[95]$ & $183(11)$ & $156(14)$ \\
& 2004 & $84[69]$ & $167(9)$ & $146(11)$ \\
& 2005 & 53 & $204(11)$ & $198(12)$ \\
HW & 2001 & 108 & $255(15)$ & $229(19)$ \\
& 2002 & 113 & $309(18)$ & $287(21)$ \\
& 2003 & 84 & $224(14)$ & $206(16)$ \\
& 2004 & 90 & $243(14)$ & $225(17)$ \\
& 2005 & 90 & $231(13)$ & $211(17)$ \\
& & &
\end{tabular}

Numbers in square brackets are from Oren et al. (2006) and the percent error of GEP and RE is listed in parentheses. Flux units are $\mathrm{g} \mathrm{C} \mathrm{m}^{-2}$ year $^{-1}$. based on the variance of monthly parameter values using a Monte Carlo simulation with 100 realizations. $\varepsilon$ in the EC system ('uniform systematic $\varepsilon$ ') was estimated using the variance of nighttime ET measurements made under non-turbulent conditions in the absence of radiative perturbations (Cava et al., 2004), a situation that should result in zero flux. These two $\varepsilon$ sources were combined to provide an estimate of total error; unlike Oren et al. (2006), the spatial component of EC $\varepsilon$ is not considered here. We used the variance calculated from the beta parameter of the Laplacian distribution in this analysis (Richardson and Hollinger, 2005); thus, NEE $\varepsilon$ terms $\left(\varepsilon_{\mathrm{NEE}}\right)$ are in general slightly smaller than those reported in Oren et al. (2006) (Table 6).

$\mathrm{RE}$ is a component of NEE and the covariance between $\varepsilon_{\mathrm{NEE}}$ and $\varepsilon_{\mathrm{RE}}$ must be taken into account when estimating $\varepsilon_{\mathrm{GEP}}$ error. Calculated this way, $\varepsilon_{\mathrm{GEP}}$ averaged $16 \%$ of GEP and $\varepsilon_{\mathrm{RE}}$ averaged $17 \%$ of RE, noting that the magnitude of the former is generally greater because the forested ecosystems represented a strong $\mathrm{C}$ sink. These relative error estimates are broadly consistent with but slightly greater than estimates from other flux studies (Meyers, 2001; Wilson and Meyers, 
2001) and represent a conservative $\varepsilon$ estimate for NRHgenerated GEP and RE values.

\section{Summary and conclusion}

This study is the first to explore the effect of vegetation cover, and thereby different momentum roughness properties and $u_{*}$ characteristics (Fig. 1), on C flux estimates generated by a suite of FPMs with the goal of determining which FPM is most robust across ecosystem type given prior flux estimates. We demonstrated that the choice of FPM can influence understanding of long-term variation in $\mathrm{C}$ flux - including the ability to estimate whether an ecosystem acts as a $\mathrm{C}$ source or sink in a given year - and can change the apparent ecosystem response to climatic events such as droughts and ice storms (Fig. 2, Table 4). Results showed that simpler FPMs (namely, the AQ10 and RH) produced estimates of $\mathrm{C}$ flux magnitude or variability that were not substantiated by independent measurements. The 'non-rectangular hyperbolic method' of Gilmanov et al. (2003) generated NEE, GEP, and RE estimates that best matched the magnitude and interannual variability of independent estimates across ecosystem types. Thus, a complex method that employs daytime EC data to estimate RE was the most robust in the case of these three ecosystems. These results agree with Juang et al. (2006), who found that nighttime RE measurements from the intercept of the light response curve agreed with estimates from a constrained source optimization on $\mathrm{CO}_{2}$ profile data from PP. However, across EC research sites, simpler methodologies based on nighttime data are more commonly used (e.g., Falge et al., 2001). If the use of nighttime data for RE estimation is preferred, the short-time exponential method of Reichstein et al. (2005) provided flux estimates that were nearer to the expected magnitudes, although in some cases interannual flux variability was unexpectedly large.

The information content (IC) of $\mathrm{NEE}_{\mathrm{d}}$ was not altered by gap-filling in both the probability and wavelet domains, but nighttime gap-filling altered both the probabilistic and spectral structure of the RE time series. In particular, the wavelet analysis suggests that RE gap-filling added a high degree of 'organization' originating from the surrogate variables or assumptions used in the gap-filling and did not replicate the variability of the time series, which exhibited some characteristics of noise at high frequencies. Despite these limitations, EC-based RE estimates roughly matched the magnitude of independent data estimates over longer-term (e.g., annual) time scales when an appropriate FPM (namely, the NRH) was used. Based on this analysis, we suggest that more focus be placed on methods that use daytime NEE data for RE (and thereby GEP) estimation when interpreting EC data when possible.

\section{Acknowledgements}

Support for this study was provided by the Department of Energy (DOE) through the FACE-FACTS and Terrestrial Carbon Processes (TCP) programs, by the National Institute of Global Environmental Change (NIGEC) through the Southeast Regional Center at the University of Alabama, Tuscaloosa (DOE cooperative agreement DE-FC030-90ER61010) and by the SERCNIGEC RCIAP Research Program. We would like to thank H.R. McCarthy for helpful comments on the manuscript and K. Wesson, C.-T. Lai, Y. Parashkevov, H. McCarthy, H.-S Kim, A.C. Oishi, K. Schäfer, B. Poulter, E. Ward, J. Pippen, R. LaMorte, R. Nettles, K. Lewin, G. Hon, A. Mace and J. Nagy for logistical assistance in the Duke Forest. Kurt Johnsen of the USDA Forest Service Southern Forest Research Station provided estimates of bulk soil C.

\section{Appendix A. Estimating the contribution of the clear-cut to $\mathrm{C}$ exchange at $\mathrm{HW}$}

A clear-cut on private land within the extent of HW $200 \mathrm{~m}$ south of the tower occurred in late November 2002 (see Fig. 1 in Stoy et al., 2006). We restrict the analysis of its effects on flux measurements beginning January 2003, as December 2002 was dominated by the ice storm and cold conditions that resulted in low observed RE. We used the two-dimensional representation of the footprint model of Hsieh et al. (2000) after Detto et al. (2006) to quantify the fraction of the HW flux footprint encompassed by the private land clear-cut for each 30-min measurement period. We then conducted a sensitivity analysis by filtering data for which the percent of the footprint in the clear-cut exceeded certain thresholds. In this way, we estimated the NEE, GEP, and RE that would have resulted had the clear-cut not occurred.

Measurements taken when the wind comes from the south or southwest are more likely to experience footprint contamination due to the clear-cut, but these conditions commonly occur during the growing season and are usually associated with a favorable climate. To test for any effects of selectively removing data, we also applied the footprint filtering procedure on 2001 and 2002 NEE data as a control, and expected that the 


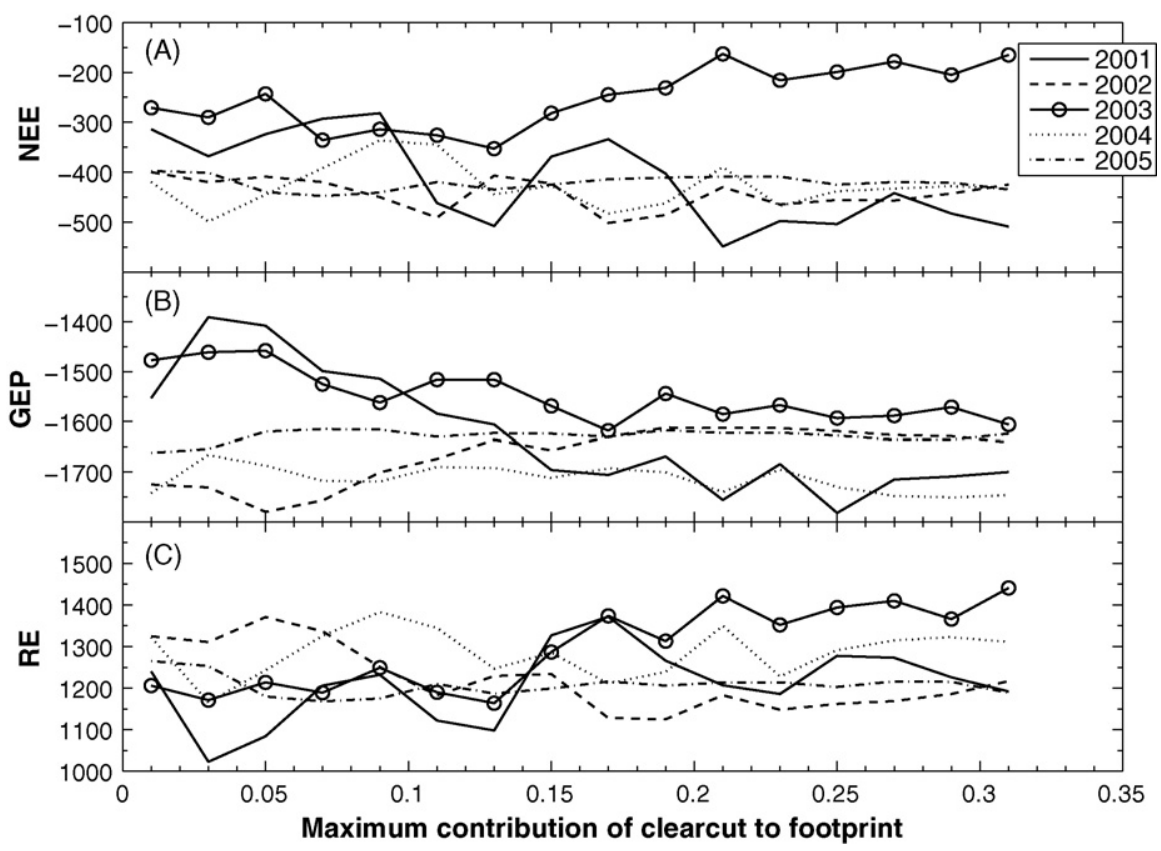

Fig. A1. The impacts of selectively filtering the clear-cut contribution to the flux footprint on annual net ecosystem exchange (NEE, A), gross ecosystem productivity (GEP, B) and ecosystem respiration (RE, C) at the hardwood forest ecosystem (HW). The analytical footprint model of Hsieh et al. (2000) extended to two dimensions by Detto et al. (2006) is used. 'Maximum contribution of footprint to clear-cut' is the fraction of footprint area within the dimensions of the clear-cut.

magnitude of NEE would decrease when measurements collected under relatively ideal climactic conditions were selectively removed.

Fig. A1 shows the impact of filtering fluxes on NEE, GEP, and RE estimates (using the NRHM). The right hand side of Fig. A1 displays flux estimates without filtering (i.e., the area of the clear-cut is allowed to comprise over $30 \%$ of the footprint) and the left hand side represents a strong filter (i.e., measurements are filtered if the clear-cut comprises only $1 \%$ of the footprint). Strengthening the filter to remove fluxes with $<1 \%$ potential clear-cut contamination had the potential to retain too few points with which to obtain stable estimates of annual flux.

NEE during 2001, 2002, 2004 and 2005 showed a similar response to selective filtering; the magnitude of NEE estimates decreases, although not monotonically, as the strength of filter is increased (from right to left on the abscissa). The reduction in NEE was expected because favorable climate is primarily associated with south and southwesterly prevailing winds from the direction of the clear-cut as mentioned. NEE estimates for 2003 differ from other years in that their magnitude increases from -150 to $-300 \mathrm{~g} \mathrm{C} \mathrm{m}^{-2}$ year $^{-1}$ as the strength of the clear-cut filter increases. The increase in NEE magnitude was attributable to a ca.
$100 \mathrm{~g} \mathrm{C} \mathrm{m}^{-2}$ year $^{-1}$ decrease in the magnitude of GEP (Fig. A1B) and a $250 \mathrm{~g} \mathrm{C} \mathrm{m}^{-2}$ year $^{-1}$ decrease in RE (Fig. A1C). After applying the clear-cut filter, GEP estimates in 2001 and 2003 are similar and $200 \mathrm{~g} \mathrm{C} \mathrm{m}^{-2}$ year $^{-1}$ smaller in magnitude than 2002 and 2004. RE estimates are also similar and within $100 \mathrm{~g} \mathrm{C} \mathrm{m}^{-2}$ year $^{-1}$ for all years. Taking into account the fact that the magnitude of NEE estimates in other years decreased between 25 and $175 \mathrm{~g} \mathrm{C} \mathrm{m}^{-2}$ year $^{-1}$ from the weakest to strongest filter, the best estimate of 2003 NEE at HW is on the order of $-400 \mathrm{~g} \mathrm{C} \mathrm{m}^{-2}$ year $^{-1}$ (Table 4). This accounts for the observed NEE of $-150 \mathrm{~g} \mathrm{C} \mathrm{m}^{-2}$ year $^{-1}$, adds $-150 \mathrm{~g} \mathrm{C} \mathrm{m}^{-2}$ year $^{-1}$ from filtering out clear-cut effects, and $-100 \mathrm{~g} \mathrm{C} \mathrm{m}^{-2}$ year $^{-1}$ to account for the fact that ideal climatic conditions were selectively filtered. Accordingly, adjusted 2003 HW RE and GEP estimates are on the order of 1250 and $-1650 \mathrm{~g} \mathrm{C} \mathrm{m}^{-2}$ year $^{-1}$, respectively (Table 4).

\section{Appendix B. Flux estimates from the AQ10 and RH methods}

C flux estimates from the AQ10 and RH for each ecosystem and measurement year are presented in Table B1. 
Table B1

Estimates of net ecosystem exchange (NEE), ecosystem respiration (RE), and gross ecosystem productivity (GEP) at the old field (OF), pine plantation (PP) and hardwood forest (HW) ecosystems

\begin{tabular}{|c|c|c|c|}
\hline Ecosystem & Year & AQ10 & RH \\
\hline \multicolumn{4}{|l|}{ NEE } \\
\hline \multirow[t]{5}{*}{ OF } & 2001 & 570 & 150 \\
\hline & 2002 & 670 & 60 \\
\hline & 2003 & 220 & -220 \\
\hline & 2004 & 70 & -140 \\
\hline & 2005 & 320 & 150 \\
\hline \multirow[t]{5}{*}{$\mathrm{PP}$} & 2001 & -240 & -530 \\
\hline & 2002 & 210 & -420 \\
\hline & 2003 & -170 & -290 \\
\hline & 2004 & -610 & -580 \\
\hline & 2005 & -840 & -740 \\
\hline \multirow[t]{5}{*}{ HW } & 2001 & 170 & -680 \\
\hline & 2002 & 190 & -680 \\
\hline & 2003 & -160 & -740 \\
\hline & 2004 & -370 & -690 \\
\hline & 2005 & -390 & -800 \\
\hline \multicolumn{4}{|l|}{ GEP } \\
\hline \multirow[t]{5}{*}{ OF } & 2001 & -1690 & -1290 \\
\hline & 2002 & -1490 & -920 \\
\hline & 2003 & -1820 & -1330 \\
\hline & 2004 & -1860 & -1160 \\
\hline & 2005 & -1530 & -1000 \\
\hline \multirow[t]{5}{*}{$\mathrm{PP}$} & 2001 & -2910 & -1900 \\
\hline & 2002 & -3170 & -1680 \\
\hline & 2003 & -2080 & -1860 \\
\hline & 2004 & -2180 & -2050 \\
\hline & 2005 & -2510 & -2560 \\
\hline \multirow[t]{5}{*}{ HW } & 2001 & -2160 & -1610 \\
\hline & 2002 & -2360 & -1470 \\
\hline & 2003 & -2000 & -1430 \\
\hline & 2004 & -2140 & -1540 \\
\hline & 2005 & -1970 & -1750 \\
\hline \multicolumn{4}{|l|}{ RE } \\
\hline \multirow[t]{5}{*}{ OF } & 2001 & 2270 & 1430 \\
\hline & 2002 & 2160 & 980 \\
\hline & 2003 & 2040 & 1110 \\
\hline & 2004 & 1930 & 1020 \\
\hline & 2005 & 1850 & 1150 \\
\hline \multirow[t]{5}{*}{ PP } & 2001 & 2670 & 1370 \\
\hline & 2002 & 3390 & 1260 \\
\hline & 2003 & 1910 & 1560 \\
\hline & 2004 & 1580 & 1470 \\
\hline & 2005 & 1670 & 1810 \\
\hline \multirow[t]{5}{*}{ HW } & 2001 & 2320 & 930 \\
\hline & 2002 & 2550 & 790 \\
\hline & 2003 & 1840 & 690 \\
\hline & 2004 & 1770 & 850 \\
\hline & 2005 & 1590 & 950 \\
\hline
\end{tabular}

'AQ10' uses the $Q_{10}$ respiration equation and RH uses a rectangular hyperbolic fit. Units are $\mathrm{g} \mathrm{C} \mathrm{m}^{-2}$ year $^{-1}$.

\section{References}

Arrhenius, S., 1889. Über die Reaktionsgeschwindigkeit bei der Inversion von Rohrzucker durch Sauren. Z. Phys. Chem. 4, 226-248.

Baldocchi, D., Falge, E., Gu, L.H., Olson, R., Hollinger, D., Running, S., Anthoni, P., Bernhofer, C., Davis, K., Evans, R., Fuentes, J., Goldstein, A., Katul, G., Law, B., Lee, X.H., Malhi, Y., Meyers, T., Munger, W., Oechel, W., Paw, U.K.T., Pilegaard, K., Schmid, H.P., Valentini, R., Verma, S., Vesala, T., Wilson, K., Wofsy, S., 2001. FLUXNET: a new tool to study the temporal and spatial variability of ecosystem-scale carbon dioxide, water vapor, and energy flux densities. Brit. Am. Meteorol. Soc. 82, 2415-2434.

Barford, C.C., Wofsy, S.C., Goulden, M.L., Munger, J.W., Pyle, E.H., Urbanski, S.P., Hutyra, L., Saleska, S.R., Fitzjarrald, D., Moore, K., 2001. Factors controlling long- and short-term sequestration of atmospheric $\mathrm{CO}_{2}$ in a mid-latitude forest. Science 294, 16881691.

Braswell, B.H., Sacks, W.J., Linder, E., Schimel, D.S., 2005. Estimating diurnal to annual ecosystem parameters by synthesis of a carbon flux model with eddy covariance net ecosystem exchange observations. Global Change Biol. 11, 335-355.

Campbell, G.S., Norman, J.M., 1998. An Introduction to Environmental Biophysics. Springer, New York.

Cava, D., Giostra, U., Siqueira, M.B.S., Katul, G.G., 2004. Organized motion and radiative perturbations in the nocturnal canopy sublayer above an even-aged pine forest. Bound. Layer Meteorol. 112, $129-157$.

Detto, M., Montaldo, N., Albertson, J.D., Mancini, M., Katul, G.G., 2006. Soil moisture and vegetation controls on evapotranspiration in a heterogeneous Mediterranean ecosystem on Sardinia, Italy. Water Resour. Res. 42, W08419, doi:10.1029/2005WR004693.

Ellsworth, D.S., Oren, R., Huang, C., Phillips, N., Hendrey, G.R., 1995. Leaf and canopy responses to elevated $\mathrm{CO}_{2}$ in a pine forest under free-air $\mathrm{CO}_{2}$ enrichment. Oecologia 104, 139-146.

Falge, E., Baldocchi, D., Olson, R., Anthoni, P., Aubinet, M., Bernhofer, C., Burba, G., Ceulemans, R., Clement, R., Dolman, H., Granier, A., Gross, P., Grunwald, T., Hollinger, D., Jensen, N.O., Katul, G., Keronen, P., Kowalski, A., Lai, C.T., Law, B.E., Meyers, T., Moncrieff, J., Moors, E., Munger, J.W., Pilegaard, K., Rannik, U., Rebmann, C., Suyker, A., Tenhunen, J., Tu, K., Verma, S., Vesala, T., Wilson, K., Wofsy, S., 2001. Gap filling strategies for defensible annual sums of net ecosystem exchange. Agric. For. Meteorol. 107, 43-69.

Gilmanov, T.G., Verma, S.B., Sims, P.L., Meyers, T.P., Bradford, J.A., Burba, G.G., Suyker, A.E., 2003. Gross primary production and light response parameters of four southern plains ecosystems estimated using long-term $\mathrm{CO}_{2}$-flux tower measurements. Global Biogeochem. Cy. 17, 1071 doi:10.1029/2002GB002023.

Goulden, M.L., Daube, B.C., Fan, S.-M., Sutton, D.J., Bazzaz, A., Munger, J.W., Wofsy, S.C., 1997. Physiological responses of a black spruce forest to weather. J. Geophys. Res. Atmos. 102, 28987-28996.

Gu, L.H., Falge, E.M., Boden, T., Baldocchi, D.D., Black, T.A., Saleska, S.R., Suni, T., Verma, S.B., Vesala, T., Wofsy, S.C., $\mathrm{Xu}$, L.K., 2005. Objective threshold determination for nighttime eddy flux filtering. Agric. For. Meteorol. 128, 179-197.

Hagen, S.C., Braswell, B.H., Linder, E., Frolking, S., Richardson, A.D., Hollinger, D.Y., 2006. Statistical uncertainty of eddy fluxbased estimates of gross ecosystem carbon exchange at Howland Forest. Maine. J. Geophys. Res. Atmos. 111, D08S03 doi:10.1029/ 2005JD006154. 
Hamilton, J.G., De Lucia, E.H., George, K., Naidu, S.L., Finzi, A.C., Schlesinger, W.H., 2002. Forest carbon balance under elevated $\mathrm{CO}_{2}$. Oecologia 131, 250-260.

Hanson, P.J., Amthor, J.S., Wullschleger, S.D., Wilson, K.B., Grant, R.F., Hartley, A., Hui, D., Hunt Jr., E.R., Johnson, D.W., Kimball, J.S., King, A.W., Luo, Y., McNulty, S.G., Sun, G., Thornton, P.E., Wang, S., Williams, M., Baldocchi, D.D., Cushman, R.M., 2004. Oak forest carbon and water simulations: model intercomparisons and evaluations against independent data. Ecol. Monogr. 74, 443489.

Hollinger, D.Y., Richardson, A.D., 2005. Uncertainty in eddy covariance measurements and its application to physiological models. Tree Physiol. 25, 873-885.

Hsieh, C.I., Katul, G., Chi, T., 2000. An approximate analytical model for footprint estimation of scalar fluxes in thermally stratified atmospheric flows. Adv. Water Resour. 23, 765-772.

Hui, D.F., Wan, S.Q., Su, B., Katul, G., Monson, R., Luo, Y.Q., 2004. Gap-filling missing data in eddy covariance measurements using multiple imputation (MI) for annual estimations. Agric. For. Meteorol. 121, 93-111.

Janssens, I.A., Pilegaard, K., 2003. Large seasonal changes in Q(10) of soil respiration in a beech forest. Global Change Biol. 9, 911918.

Juang, J.-Y., Katul, G.G., Siqueira, M.B.S., Stoy, P.C., Palmroth, S., McCarthy, H.R., Kim, H.-S., Oren, R., 2006. Modeling nighttime ecosystem respiration from measured $\mathrm{CO}_{2}$ concentration and air temperature profiles using inverse methods. J. Geophys. Res. Atmos. 111, D08S05 doi:10.1029/2005JD005976.

Katul, G.G., Hsieh, C.-I., Bowling, D., 1999. Spatial variability of turbulent fluxes in the roughness sublayer of an even-aged pine forest. Bound. Layer Meteorol. 93, 1-28.

Katul, G.G., Lai, C.-T., Albertson, J.D., Vidakovic, B., Schäfer, K.V.R., Hsieh, C.I., Oren, R., 2001a. Quantifying the complexity in mapping energy inputs and hydrologic state variables into landsurface fluxes. Geophys. Res. Lett. 28, 3305-3307.

Katul, G.G., Lai, C.-T., Schäfer, K.V.R., Vidakovic, B., Albertson, J.D., Ellsworth, D.S., Oren, R., 2001b. Multiscale analysis of vegetation surface fluxes: from seconds to years. Adv. Water Resour. 24, 1119-1132.

Lai, C.-T., Katul, G.G., 2000. The dynamic role of root-water uptake in coupling potential to actual transpiration. Adv. Water Resour. 23, 427-439.

Lai, C.T., Katul, G., Butnor, J., Ellsworth, D., Oren, R., 2002. Modelling night-time ecosystem respiration by a constrained source optimization method. Global Change Biol. 8, 124-141.

Law, B.E., Falge, E., Gu, L., Baldocchi, D.D., Bakwin, P., Berbigier, P., Davis, K., Dolman, A.J., Falk, M., Fuentes, J.D., Goldstein, A., Granier, A., Grelle, A., Hollinger, D., Janssens, I.A., Jarvis, P., Jensen, N.O., Katul, G., Mahli, Y., Matteucci, G., Meyers, T., Monson, R., Munger, W., Oechel, W., Olson, R., Pilegaard, K., Paw, K.T., Thorgeirsson, H., Valentini, R., Verma, S., Vesala, T., Wilson, K., Wofsy, S., 2002. Environmental controls over carbon dioxide and water vapor exchange of terrestrial vegetation. Agric. For. Meteorol. 113, 97-120.

Lee, X., Fuentes, J.D., Staebler, R.M., Neumann, H.H., 1999. Longterm observation of the atmospheric exchange of $\mathrm{CO}_{2}$ with a temperate deciduous forest in southern Ontario, Canada. J. Geophys. Res. Atmos. 104, 15975-15984.

Lloyd, J., Taylor, J.A., 1994. On the temperature dependence of soil respiration. Funct. Ecol. 8, 315-323.

Luo, Y.Q., Medlyn, B.E., Hui, D.F., Ellsworth, D., Reynolds, J., Katul, G.G., 2001. Gross primary productivity in Duke Forest: modeling synthesis of $\mathrm{CO}_{2}$ experiment and eddy-flux data. Ecol. Appl. 11, 239-252.

McCarthy, H.R., Oren, R., Johnsen, K.H., Pritchard, S.G., Davis, M.A., Maier, C., Kim, H.-S., 2006. Ice storms and management practices interact to affect current carbon sequestration in forests with potential mitigation under future $\mathrm{CO} 2$ atmosphere. J. Geophys. Res. Atmos 111, D15103, doi:10.1029/2005JD 006428.

Meyers, T.P., 2001. A comparison of summertime water and $\mathrm{CO}_{2}$ fluxes over rangeland for well watered and drought conditions. Agric. For. Meteorol. 106, 205-214.

Morgenstern, K., Black, T.A., Humphreys, E.R., Griffis, T.J., Drewitt, G.B., Cai, T.B., Nesic, Z., Spittlehouse, D.L., Livingstone, N.J., 2004. Sensitivity and uncertainty of the carbon balance of a Pacific Northwest Douglas-fir forest during an El Nino La Nina cycle. Agric. For. Meteorol. 123, 201-219.

Mortazavi, B., Chanton, J.P., Prater, J.L., Oishi, A.C., Oren, R., Katul, G.G., 2005. Temporal variability in ${ }^{13} \mathrm{C}$ of respired $\mathrm{CO}_{2}$ in a pine and a hardwood forest subject to similar climatic conditions. Oecologia 142, 57-69.

Novick, K.A., Stoy, P.C., Katul, G.G., Ellsworth, D.S., Siqueira, M.B.S., Juang, J., Oren, R., 2004. Carbon dioxide and water vapor exchange in a warm temperate grassland. Oecologia 138, 259274.

Oosting, H.J., 1942. An ecological analysis of the plant communities of Piedmont, North Carolina. Am. Midl. Nat. 28, 1-126.

Oren, R., Ewers, B.E., Todd, P., Phillips, N., Katul, G., 1998. Water balance delineates the soil layer in which moisture affects canopy conductance. Ecol. Appl. 8, 990-1002.

Oren, R., Pataki, D.E., 2001. Transpiration in response to variation in microclimate and soil moisture in southeastern deciduous forests. Oecologia. 127, 549-559.

Oren, R., Hsieh, C.-I., Stoy, P.C., Albertson, J., McCarthy, H.R., Harrell, P., Katul, G.G., 2006. Estimating the uncertainty in annual net ecosystem carbon exchange: spatial variation in turbulent fluxes and sampling errors in eddy-covariance measurements. Global Change Biol. 12, 883-896.

Palmroth, S., Maier, C.A., McCarthy, H.R., Oishi, A.C., Kim, H.-S., Johnsen, K.H., Katul, G.G., Oren, R., 2005. Contrasting responses to drought of the forest floor $\mathrm{CO}_{2}$ efflux in a loblolly pine plantation and a nearby oak-hickory forest. Global Change Biol. 11, 421-434.

Pataki, D.E., Oren, R., 2003. Species differences in stomatal control of water loss at the canopy scale in a mature bottomland deciduous forest. Adv. Water Resour. 26, 1267-1278.

Pataki, D.E., Oren, R., Katul, G.G., Sigmon, J., 1998. Canopy conductance of Pinus taeda, Liquidambar styraciflua and Quercus phellos under varying atmospheric and soil water conditions. Tree Physiol. 18, 307-315.

Poggi, D., Katul, G.G., Albertson, J.D., 2004. Momentum transfer and turbulent kinetic energy budgets within a dense model canopy. Bound. Layer Meteorol. 111, 589-614.

Reichstein, M., Falge, E., Baldocchi, D., Papale, D., Aubinet, M., Berbigier, P., Bernhofer, C., Buchmann, N., Gilmanov, T.G., Granier, A., Grünwald, T., Havránková, K., Ilvesniemi, H., Janous, D., Knohl, A., Laurila, T., Lohila, A., Loustau, D., Matteucci, G., Meyers, T., Miglietta, F., Ourcival, J.-M., Pumpanen, J., Rambal, S., Rotenberg, E., Sanz, M., Tenhunen, J., Seufert, G., Vaccari, F., Vesala, T., Yakier, D., Valentini, R., 2005. On the separation of net ecosystem exchange into assimilation and ecosystem respiration: review and improved algorithm. Global Change Biol. 11, 14241439. 
Richardson, A.D., Hollinger, D.Y., 2005. Statistical modeling of ecosystem respiration using eddy covariance data: maximum likelihood parameter estimation, and Monte Carlo simulation of model and parameter uncertainty, applied to three simple models. Agric. For. Meteorol. 131, 191-208.

Richardson, A.D., Hollinger, D.Y., Burba, G.G., Davis, K.J., Flanagan, L.B., Katul, G.G., Munger, J.W., Ricciuto, D.M., Stoy, P.C., Suyker, A.E., Verma, S.B., Wofsy, S.C., 2006. A multi-site analysis of uncertainty in tower-based measurements of carbon and energy fluxes. Agric. For. Meteorol. 136, 1-18.

Ruimy, A., Jarvis, P.G., Baldocchi, D.D., Saugier, B., 1995. $\mathrm{CO}_{2}$ fluxes over plant canopies and solar radiation: a review. Adv. Ecol. Res. 26, 1-68.

Ruxton, G.D., 2006. The unequal variance $t$-test is an underused alternative to Student's $t$-test and the Mann-Whitney $U$ test. Behav. Ecol. 17, 688-690.

Sarmiento, J., Wofsy, S. (co-chairs), 1999. A US carbon cycle science plan: a report of the carbon and climate working group, US Global Change Research Program, Washington, DC.

Schäfer, K.V.R., Oren, R., Ellsworth, D.S., Lai, C.T., Herrick, J.D., Finzi, A.C., Richter, D.D., Katul, G.G., 2003. Exposure to an enriched $\mathrm{CO}_{2}$ atmosphere alters carbon assimilation and allocation in a pine forest ecosystem. Global Change Biol. 9, 1378-1400.

Shannon, C.E., 1948. A mathematical theory of communication. AT\&T Tech. J. $27 \quad 379-423$ and 623-656.

Stoy, P.C., Katul, G.G., Siqueira, M.B.S., Juang, J.-Y., McCarthy, H.R., Kim, H.-S., Oishi, A.C., Oren, R., 2005. Variability in net ecosystem exchange from hourly to interannual time scales at adjacent pine and hardwood forests: a wavelet analysis. Tree Physiol. 25, 887-902.

Stoy, P.C., Katul, G.G., Siqueira, M.B.S., Juang, J.-Y., McCarthy, H.R., Oishi, A.C., Uebelherr, J.M., Kim, H.-S., Oren, R., 2006. Separating the effects of climate and vegetation on evapotranspiration along a successional chronosequence in the southeastern US. Global Change Biol. 12, 2115-2135.

Webb, E.K., Pearman, G.I., Leuning, R., 1980. Correction of flux measurements for density effects due to heat and water vapour transfer. Q. J. Roy. Meteor. Soc. 106, 85-100.

Wilson, K.B., Meyers, T.P., 2001. The spatial variability of energy and carbon dioxide fluxes at the floor of a deciduous forest. Bound Layer Meteorol. 98, 443-473. 